\title{
Die Datierung des Dekalogs
}

von

G. Wildeboer.

In dieser Zeitschrift, 24 Jahrg. I904, S. I7 ff. hat Professor Matthes versucht, seine Festsetzung des 7. Jahrhunderts als der Zeit der Abfassung des Dekalogs aufrecht zu erhalten. Wie wir es von ihm gewohnt sind, ist er aufrichtig bestrebt, den gegnerischen Ansichten gerecht zu werden. Einerseits wendet er sich hauptsächlich gegen Eerdmans, andererseits auch gegen mich. Mir stimmt er darin unbedingt bei, daß dem Dekalog eine hohe religiös-sittliche Bedeutung zuzuschreiben sei. Aber eben darum ist er geneigt, denselben nicht in die mosaische Periode $\mathrm{zu}$ setzen, sondern in eine viel spätere Periode der israelitischen Religionsgeschichte. Er gilt ihm als ein "compendium legis". „Er resumire“ - wie Kuenen es 1887 als möglich hinstellte - „was die Jahwepropheten schon ausgesprochen hätten“. Den Schriftsteller des Dekalogs „mache man zum Zeitgenossen Manasses“.

Doch werden wir Prof. Matthes nicht gerecht, wenn wir sagen, daß er für diese Datierung aus dogmatischen oder religionsgeschichtlichen Gründen eintritt. Seine Argumentation ist eben darum so interessant und anziehend, weil er hauptsächlich mit geschichtlichen Beweisen operiert. Matthes urteilt, daß der Dekalog nicht „,den Stempel jenes [d. h. des mosaischen] Zeitalters an sich trage, sondern den des königlich-prophetischen in Juda“. „Dies geht m. 
E." - so schreibt er - „hervor aus der nationalen Lage, in der er wurzelt; aus der Sprache, in der er verfaßt ist; aus dem sozialen, gottesdienstlichen und religiös-sittlichen Zustande, den er zur Voraussetzung hat". Über diese drei Argumentenreihen will ich einige kurze Bemerkungen machen.

I. Die nationale Lage. Matthes findet bei Eerdmans einen Widerspruch. Auf S. 33 seiner Abhandlung schrieb Eerdmans: „Wir wissen, daß die Stämme, nachdem sie sich in Kanaan angesiedelt hatten, keine Einheit bildeten". Und S. 32 schreibt er: „Seit der Wüstenzeit ist Jahwe der Gott Israels, d. h. des Ganzen, der Nation; das ist das einstimmige Zeugnis der israelitischen Literatur". Eerdmans hätte sich m. E. klarer und genauer aussprechen können. Doch glaube ich, daß der Widerspruch bei $E$. nicht so absolut ist, wie Matthes meint. Die Einheit des Volkes Israel war im Anfang in Kanaan nicht so fest und so konsolidiert wie nachher in der Königszeit. Aber eine gewisse Einheit, eine Verbindung der Stämme, wenn nicht aller so doch der vornehmsten, ist doch für den Wüstenzug und die Eroberung geschichtlich bezeugt. Alle Schichten der pentateuchischen Tradition, sowie die Propheten des 8. Jahrhunderts weisen darauf hin. Mag auch nach den ersten Eroberungskriegen die Vereinigung der Stämme wieder lockcr geworden sein, es geht doch nicht an, den Stämmebund ganz zu leugnen. Man könnte ebensogut die Geschichtlichkeit des davidisch-salomonischen Reiches bestreiten, weil der größte Teil der Königsperiode nur eine Spaltung in Efraim und Juda kennt. . Und hat es in der Wüste einen Stämmebund der Benê-Israel gegeben - so kann es gar nicht Wunder nehmen, daß damals ein knappes Gesetz von zehn Worten gegeben wurde, hauptsächlich um die Verpflichtungen des Bundes der Stämme unter einander 
und die Verpflichtungen diese Stämmen ihrem Gott gegenüber $z u$ verzeichnen.

2. Die Sprache und die Schrift des Dekalogs. "Seine Sprache ist die der prophetisch-königlichen Zeit." „Hebräisch ist Kanaanäisch, die von den Kanaanäern entlehnte Sprache“. Wäre der Dekalog mosaisch, so müsste das Gesetz in südsemitischer oder arabischer Mundart verfaßt sein. „In Arabia Petraea haben die Stämme natürlich einen arabischen Dialekt gesprochen; vor ihrem Eintritt und Wohnen in Kanaan selbst kein Wort hebräisch verstanden".

Von der Geschichte der hebräischen Sprache überhaupt, besonders von der ältesten Periode dieser Geschichte wissen wir recht wenig. Und den Dialekt von Nomadenstämmen der Sinaiwüste im I3. Jahrhundert v. Chr. zu bestimmen, sie mögen mehr nördlich gewohnt haben, wie der Jahvist will, oder mehr südlich, wie die jüngeren Quellen die Sache darstellen, ist ungemein schwer. Doch glaube ich, daß man hier eins nicht vergessen darf: die israelitische Vorgeschichte meldet auch, daß diese Stämme, aus Aram stammend (Deut. 26, 5), vor ihrem Aufenthalt in Gosen schon in Kanaan herumgeirrt waren. Und als sie unter Moses Führung in der Sinaiwüste verkehrten, wohnten vielleicht schon viele ihrer Brüder (besonders Teile der Lea- und Zilpa-Stämme) in Kanaan. Mit diesen kanaanäischen Brüdern standen sie doch wohl in Beziehung. Sollte ihr Dialekt sich nicht mehr dem Kanaanäischen als dem Arabischen genähert haben? ${ }^{x}$

3. Die sozialen Verhältnisse. Matthes stimmt zu, daß spätere soziale Verhältnisse besonders in den längeren

I Es ist doch bemerkenswert, daß die israelitischen Eindringlinge niemals im Verkehr mit den Kanaanitern einen Dolmetscher brauchen. 
Geboten vorkommen. Diese längeren Gebote enthalten jedoch keine [speziell deuteronomischen] Zusätze, das ganze Gesetz der Zehn Worte gilt ihm als deuteronomisch. Ohne diese Zusätze würde manches Gebot unverständlich sein! Z. B. „Gedenkt des Sabbathtages“. „So blieb die Frage zu beantworten: auf welche Weise muß er gehalten werden? Fehlte die Vorschrift der Ruhe, so war mit dem Gebote nichts Wesentliches beabsichtigt noch erreicht".

Ich glaube nicht, $\mathrm{da} ß$ man bei der Voraussetzung von den deuteronomischen oder priesterlichen Zusätzen, anzunehmen braucht, daß z. B. das 4. Gebot ursprünglich so außerordentlich kurz gewesen wäre, wie Matthes es formuliert. Es kann doch auch diese Form gehabt haben: "Gedenkt des Sabbaths um denselben zu heiligen" (oder: denselben heiligend) d. h. ihn zu Ehren Jahwes von den anderen Tagen der Woche absondernd.

Nur, wenn man annimmt, daß ursprünglich auch die längeren Gebote so kurz oder fast so kurz waren wie das 6., 7., 8. und 9., versteht man, wie es gekommen ist, daß das Sabbathgebot in Ex. 20 und Deut 5 verschiedenartig motiviert ist. Wäre die Motivierung ursprünglich, so würde es nicht $z u$ erklären sein, wie man in einem so feierlichen Gesetz dazu gekommen sein sollte, dieselbe zu ändern.

Und dả der Dekalog, selbst mit gewissen Zusätzen, älter ist als Deuteronomium, erhellt aus dem folgenden. Deut. 24, 16 heibt es: „Nicht sollen Väter samt den Kindern hingerichtet werden, und Kinder sollen nicht samt den Vätern hingerichtet werden; es darf einer nur wegen seiner eigenen Schuld hingerichtet werden". Bekanntlich spricht 'sich hier der Individualismus, der im 7. Jahrhundert aufkommt (Jeremia 31, 29.30, Ezechiel 18, 2) deutlich aus. Und dasselbe finden wir auch bei einem der jüngeren Herausgeber des Gesetzes, in Deut. 7, 10: ,aber seinem Hasser vergilt er es an der 
eigenen Person durch Vernichtung, ohne seinem Hasser Aufschub (der Strafe) zu gewähren; an seiner eigenen Person vergilt er ihm". So scharf möglich wird hier der starre Individualismus gelehrt, während doch in Deut. 5,9 aus Ex. 20, 5.6 unverändert herübergenommen ist: ,ich, Jahwe, dein Gott, bin ein eifersüchtiger Gott, der Verschuldung der Väter an Kindern, Enkeln und Urenkeln derer heimsucht, die mich hassen". Die antike Betrachtungsweise, welche von der Solidarität der Geschlechter ausgeht, konnte also einer der jüngsten Herausgeber des deuteronomischen Gesetzes in dem allbekannten, alten Gesetze nicht abändern, wiewohl sie schnurstracks den Gedanken des Buches selbst und seinen eigenen Ideen widersprach.

Es findet sich vieles in Matthes' anregender Untersuchung, womit wir uns gerne auseinandersetzen möchten. Nur noch eine Bemerkung zum Schluß. Ich möchte noch immer Gewicht darauf legen, daß die Vorstellung des am Sinai Geschehenen in Deut. 5 nicht Fantasie sein kann. Wie Kuenen richtig verstanden hat, muß die vor-deuteronomische Überlieferung die Vorstellung enthalten haben, $\mathrm{da} B$ nur ein Dekalog am Sinai gegeben sei, und daß erst am Ende des Wüstenaufenthalts soziale und andere Gesetze von Mose erlassen seien, deren Inhalt er von Jahwe auf dem Sinai vernommen habe. Ich glaube noch immer, $\mathrm{daB}$ wenn man sich in diese Vorstellung gründlich hineindenkt, man auch von literarisch-kritischer Seite dazu kommen wird, den Dekalog wenigstens als ein uraltes, bekanntes Denkmal. in der vordeuteronomischen Tradition anzusehen (vgl. meine Literatur des A. T. \$ I, Anm. 3).

Groningen, Mai 1904 . 